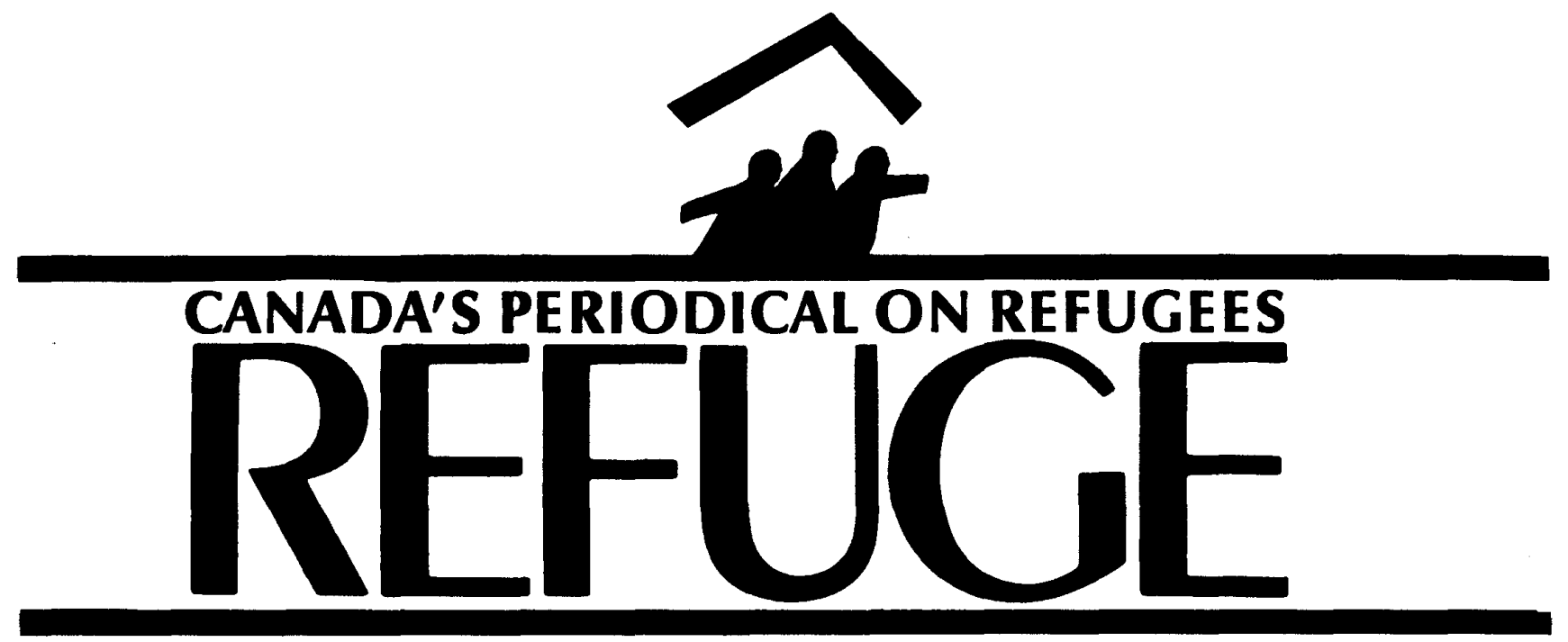

Vol. $18 \bullet$ No. 5

January 2000

\title{
Health Issues Affecting Displaced Populations The Evolution of Public Health Response in Emergency and Post-Emergency Phases of Complex Emergencies
}

Introduction

The field of humanitarian response has made tremendous strides over the past decade. In the Cambodian refugee camps in the 1980s, the establishment of basic health information systems allowing for rapid response and directing health programs according to the data

\section{Paul B. Spiegel}

collected, proved a powerful tool in improving the health of the refugee populations. ${ }^{1}$ Simplebut powerfulepidemiological computer programs were developed which have proved invaluable in the field. ${ }^{2}$

As a consequence of the terrible toll of the numerous massive population displacements in Africa and Asia throughout the past two decades, the importance of implementing rapid mass measles immunization campaigns for children, methods to detect, measure and treat malnutrition, and the recognition that four main communicable diseases (measles, diarrhea, lower respiratory tract infections, and malaria (in endemic areas) during the acute phase of crises often accounted for over $70 \%$ of all deaths in the camps), has saved an incalculable number of lives. ${ }^{3-6}$

The field of disaster response has slowly professionalized over the past decade. Western-trained health professionals, whose education generally emphasizes an individual patientcentered curative approach, now have the opportunity to choose from various training programs which focus on the essential elements of managing health situations in complex emergencies (CEs), with an emphasis on public health and preventive medicine. From the numerous experiences of responding to mass population movements during the past few decades, a codification of standards of care during the acute phase of CEs has been developed, ${ }^{7}$ es- 


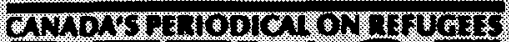
(y)

Genitre for Refupere Studies Stite 322, Tonl. Lanes Youl Viniversity

4700 Keele Sticel, Torointo Ontario, Canada Misy I IS

Thone: 1416 t $756-5663$

72x. $(416 \%, 756=5837$

Email refuge g yorkin.ca

Vol. $18 \cdot$ No. 5

January 2000

Editior

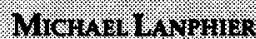

Guest Editor:

PNOUL B. STrEeEL

Technical Editor

Isreare. Dorkon

Assistant Editor

JENNIFER Mris:

French Translation

PauUL urzanozau

Reguge is dedichted to the encourage: ment of assistance to refugers by providing a fortin for shating in formation and opirion on. Canadian and intermational issues pertainumg to refugees Refuge was founded In 1981.

It is published six limes a year by the Centre for Refugee Studies, York Universily, Canada. Refuge is a non profit, independent periodical supported by private donations and by subscriptions. It is a forum for discussion, and the views expressed do not necessurity refled those of 1 ts funders or start.

AII material in Refuge may be reproduced without perinission unless copyrighted or otherwise indleated. Credit should be grven to the author or source, If named, and Refuge, SHbmissions on related issues are welcome for publication consideration.

Cumrent subsemption rates for one

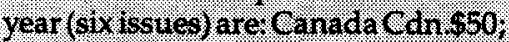
allother counthies U.S. 160 . (Chegues must be drawn gh a Canadian or a U.S. bank) Cument volume single issues are avallable at sto per copy.

Please enclose your purchase order or payment.

$158 \mathrm{~N} 02929113$ sential medication lists have been established, ${ }^{8}$ and large kits containing medical supplies for rapid response have been created and pre-positioned. ${ }^{9}$ However, responses are still based upon the early paradigms of humanitarian response and have not effectively evolved over the past 5-10 years, in terms of addressing different typologies and epidemiological disease profiles of CEs, as well as the different phases and their definitions.

\section{Typologies}

Before the fall of the Soviet Union in 1991 , most international responses to CEs, or complex humanitarian emergencies (CHEs) as they have generally been called, occurred in S-E Asia and Africa. Typically, there were numerous causes, primarily a mixture of natural (draught, flood, famine) and political instability (coups, military conflicts), which resulted in massive population displacements. These people were generally poor, both in terms of health status as well as material possessions. They often walked for days and weeks, crossing a border into a remote region of another country whose people were equally poor and had little to offer. The combination of their exhaustion and malnutrition allowed communicable diseases, often in epidemics, to ravage the population. ${ }^{5,10}$ With the disintegration of the Federal Republic of Yugoslavia in 1991/92, a different type of CE was observed, sometimes referred to as a complex political emergency (CPE).$^{11}$ These wars, often within one state, have culminated in campaigns of ethnic cleansing which have deliberately targeted civilians. Relatively healthy people were suddenly forced to flee their homes, by vehicle or by foot, to become displaced within their country or in nearby neighboring countries. The humanitarian aid system, often implemented by non-governmental organizations (NGOs), has been slow to recognize and adapt to this new typology. The skills and type of personnel needed for CPEs are often different, as are the medical supplies (including the pre-positioned supplies).

\section{Epidemiological Disease Profiles}

Disease profiles of countries often depend upon the stages of their development. Communicable diseases account for the majority of deaths in developing countries, and baseline mortality rates are higher. ${ }^{12}$ Developed countries' crude and age-specific mortality rates are much lower than developing countries. Populations live longer and noninfectious chronic diseases, such as lung, cardiac, and certain cancers account for the majority of deaths. ${ }^{12}$ The baseline epidemiological disease profile of these populations directly effect the disease profiles observed in the different crises. Furthermore, the different populations' baselinehealth status and material wealth, combined with the distance, time and mode of travel (foot vs vehicle) used to reach 'safety', as well as the remoteness of that location, all have a tremendous effect on the type and degree of morbidity and mortality observed. For example, in the recent CPEs in the Balkans, mortality rates have remained relatively low, and deaths directly related to war trauma have accounted for the majority of all mortality, while deaths due to malnutrition and communicable disease remained relatively low compared to the CHEs which have occurred in S-E Asia and Africa. ${ }^{13-16}$

\section{Phases}

CEs are generally divided into three phases- emergency, post-emergency, and repatriation/resettlement. Due to the high mortality in previous CHEs in S-E Asia and Africa, the definition of an emergency phase came to depend upon the level of mortality noted. If the mortality rate is $>1$ death $/ 10,000$ persons / day, which is approximately two times the normal baseline rate for developing countries, than the phase is considered to be an emergency. ${ }^{6}$ This definition of an emergency phase does not necessarily apply to the CPEs which have oc- 
curred in the Balkans, where overall mortality rates have often remained low, ${ }^{13,16}$ despite massive population shifts in situations which were obviously acute humanitarian crises. ${ }^{11} \mathrm{~A}$ different definition of an emergency phase for these CPEs needs to be established which takes into account the magnitude of displacement and consequent morbidity and change in circumstances (shelter, water, sanitation, source of income, etc.), rather than solely the level of mortality.

If one examines the life of a $\mathrm{CE}$, many displaced populations remain in that status for years. Yet for the most part, guidelines and indicators have only been developed for the emergency phase of a CE. ${ }^{7}$ In general, emergency phases of CHEs last 1-6 months, the time it takes to bring the mortality below the 1 death $/ 10,000$ persons/day threshold. After this period, mortality rates often stabilize and may even belower than the host country. ${ }^{17}$ Morbidity and quality of life issues then become the major concern in the post-emergency phase. Issues such as reproductive health, ${ }^{18}$ psychosocial illness, and chronic diseases are belatedly coming to the attention of humanitarian agencies. Although these issues should be addressed during the emergency phase of a CHE, it is often difficult to successfully do so when the main goal is to minimize 'excess' mortality. This problem is not necessarily the case for CPEs, where mortality may not be elevated from its baseline, and the highest priorities may indeed be reproductive health, psychosocial illness, and chronic diseases. Standards for displaced populations in the post-emergency phase need to be created and implemented.

\section{Current Refuge Issue- Health Issues Affecting Displaced Populations}

Ibelieve that this current issue of Refuge will help address some of the deficiencies in humanitarian aid listed above. The first three articles discuss established areas of CHEs - malaria, malnutrition, and water/sanitation. As these papers clearly show, resistance to antimalarial drugs and new techniques for the diagnosis of malaria, malnutrition in adolescence and adulthood, and water/sanitation issues in CPEs are rapidly evolving and NGOs must adapt to them if they are to be effective in the field. The next four articles discuss reproductive health, economic issues, and quality control and management issues in CEs. The former topic has received much attention in the past 5 years and is now becoming an integral part of humanitarian aid. The latter two topics are relatively new to the humanitarian field. All of the above issues must be considered and programs developed during the emergency phase. Whenever possible, these programs should also be implemented during that phase, and then become more comprehensive, while remaining adaptable, during the post-emergency phase. The last two articles discuss the new typology of the CPE. They highlight the similarities and differences between CHEs and CPEs, as well as provide recommendations to the NGOs responding to these crises.

\section{References}

1. Glass, R. I., P. Nieburg, and W. Gates et al. Rapid Assessment of Health Status and Preventive Medicine Needs of Newly Arrived Kampuchean Refugees, Sa Kaeo, Thailand. Lancet 1980;1(8173):868-872.

2. Dean, A. G. et al. Epi Info Version 2, second. edition, Centers for Disease Control and Prevention, 1986.

3. Toole, M.J.,P. Nieburg, and R.J.Waldman. The Association Between Inadequate Rations, Undernutrition Prevalence, and Mortality in Refugee Camps: Case Studies of Refugee Populations in Eastern Thailand, 1979-1980, and Eastern Sudan, 1984-1985. J Trop Pediatr 1988;34(5):21824.

4. Toole,M.J., R.W.Steketee, R. J.Waldman, P. Nieburg. Measles Prevention and Control in Emergency Settings. Bull World Health Organ 1989;67(4):381-8.

5. Toole, M. J. and R.J.Waldman. Refugees and Displaced Persons. War, Hunger, and Public Health. Jama 1993;270(5):600-5.

6. Centers for Disease Control and Prevention. Famine-affected, Refugee, and Displaced Populations: Recommendations for Public Health Issues. MMWR 1992;41(RR13):1-76.
7. SPHERE. Humanitarian Charter and Minimum Standards in Disaster Response. Geneva: Steering Committee for Humanitarian Response, 1998.

8. World Health Organization's Model List of Essential Drugs. 10 ed. Geneva: WHO, 1997.

9. World Health Organization: Handbook for Emergency Field Operations: WHO, 1999.

10. Toole, M. J.and R. J. Waldman. An Analysis of Mortality Trends Among Refugee Populations in Somalia, Sudan, and Thailand. Bull World Health Organ 1988;66(2):237-47.

11. Waldman, R. and G. Martone Public Health and Complex Emergencies: New Issues, New Conditions. Am J Public Health 1999;89(10):1483-5

12. World Health Report 1999: Making a Difference. Geneva:World Health Organization, 1999.

13. Centers for Disease Control and Prevention. Status of Public Health-Bosnia and Herzegovina, August-September 1993. MMWR Morb Mortal Wkly Rep 1993;42(50):973, 979-82.

14. Toole, M.J., S. Galson, and W. Brady. Are War and Public Health Compatible? Lancet 1993;341(8854):1193-6.

15. Puvacic, $Z$. and J. Weinberg. Impact on Infectious Disease in Bosnia-Hercegovina BMJ 1994;309:1207-8.

16. Spiegel, P. and P. Salama. The Epidemiology of War: Mortality During the Kosovo Conflict, 1998/99. in press Jan 2000.

17. Spiegel, P. and M. Sheik. Mortality in the Post-Emergency Phase of Displaced Populations. in press Feb 2000.

18. Inter-agency Field Manual. Reproductive Health in Refugee Situations. Geneva: UNHCR. et al., 1999: 1-135. a

Dr. Paul Spiegel was born in Toronto, Canada. $\mathrm{He}$ is a medical epidemiologist in the International Emergency and Refugee Health branch at the centers for Disease Control and Prevention in Atlanta, Georgia, U.S.

\section{Feedback?}

Questions?

Remarks?

We welcome them all.

Send to

refure@vorku.ca 